\title{
Understanding Differences between CORE and CACREP Counselors-in-Training Perceptions of Self-Efficacy
}

\author{
Sabrina Harris ${ }^{1}$, Michael Brooks ${ }^{2}$, Robin Liles ${ }^{2}$, Glacia Ethridge ${ }^{2}$, Quinton Boston ${ }^{2}$, Kacie Blalock ${ }^{2}$ \\ ${ }^{1}$ Coppin State University, United States \\ ${ }^{2}$ North Carolina A\&T State University, United States \\ Correspondence: Michael Brooks, North Carolina A\&T State University, United States.
}

Received: November 5, 2018

doi:10.11114/ijsss.v7i1.3747
Accepted: December 19, 2018 Available online: December 27, 2018

URL: https://doi.org/10.11114/ijsss.v7i1.3747

\begin{abstract}
An examination of differences in perceptions of self-efficacy between students in CORE-accredited rehabilitation counseling programs and students in CACREP -accredited clinical mental health counseling programs enrolled in practicum/internship classes is absent in the literature. Results indicated there was not a significant difference $(p=.05)$ between the total self-efficacy scores between both treatment groups (CORE and CACREP). Further, there was not a significant difference between helping skills, session management, and counseling challenging situations scores for both treatment groups (CORE and CACREP). Predictors of self-efficacy for CACREP participants consisted of prior work experience in a field other than helping. Predictors of self-efficacy for CORE participants were gender.
\end{abstract}

Keywords: rehabilitation counseling, counseling, CACREP, CORE, accreditation, clinical internship, counselors-in-training, clinical internship, practicum

\section{Introduction}

\subsection{Introduction}

On July 20, 2015, the Council on Rehabilitation Education (CORE) and the Council for Accreditation of Counseling and Related Educational Programs (CACREP) entered a Plan of Merger Agreement. With this agreement came the additional announcement that: "Beginning July 1, 2017, CACREP will carry on the mission of both organizations. (Council for Accreditation of Counseling and Related Educational Programs, 2015, para. 1)." With the merger of CACREP and CORE and the ultimate sun setting of CORE, it is imperative both rehabilitation counselors and clinical mental health counselors maintain separate professional identities to maintain the mission of each counseling specialty.

The purpose of this investigation is to examine perceptions of self-efficacy between master's level rehabilitation counseling practicum and internship students enrolled in CORE-accredited programs and master's level clinical mental health counseling practicum and internship students enrolled in CACREP-accredited programs.

Practicum and internship experiences in counselor education programs are designed to assist counselors-in-training in increasing counseling competency (Tang, Addison, LaSure-Bryant, Norman, O'Connell, \& Stewart-Sicking, 2004). Thus, the level of training a student receives, together with the quality of the practicum/internship experience may contribute to higher levels of professional self-efficacy among counselors-in- training (Tang et al., 2004).

Perceptions of self-efficacy between rehabilitation counseling interns (CORE) and clinical mental health counseling interns (CACREP) could be related to the sheer novelty of the study. Limited research has been conducted on this topic and since CORE has disseminated, there are no comparison groups to evaluate self-efficacy of students enrolled in a CORE accredited program. Due to the gaps in the literature, the researcher was unable to identify problems or errors that may have been encountered by other researchers.

As a result, the aim of this manuscript was to determine if there was a significant significant difference between CORE-accredited rehabilitation and CACREP-accredited clinical mental health counseling practicium/internship student's total self-efficacy score based off of the results from the Counselor Self-Efficacy Scale.

From the point of view of self-efficacy theory (Bandura, 1977), it is reasonable to assume that over time, counselor education and supervision positively influence counselor-in-training self-efficacy (Tang et al., 2004). For this study, the 
researcher hypothesized that there is not a difference between the total self efficacy score, helping skills self-efficacy score, the self-management self-efficacy score, and the challenging situations self-efficacy score.

To investigate perceptions of self-efficacy between master's level rehabilitation counseling practicum and internship students enrolled in CORE-accredited programs and master's level clinical mental health counseling practicum and internship students enrolled in CACREP-accredited programs, a nonexperimental, ex post facto, two group comparison design was utilized (Heppner, Wampold, \& Kivlighan, 2008).

The independent variable was counselor training (i.e., CORE-accredited rehabilitation counseling training or CACREP-accredited clinical mental health counseling training); and the dependent variable was counselor-in-training self-efficacy. For purposes of this study, the construct of self-efficacy was further divided into three sub-scales, including: helping skills, session management, and counseling challenges.

This study is important because rehabilitation counseling students who were enrolled in CORE accredited programs who did not participate in the CORE Conversion Process will not be able to obtain licensure in many states as a Licensed Practical Counselor (LPC) or become certified to provide counseling services to clients with insurance providers such as Tricare if certain requirements were not met by January $1^{\text {st }}, 2017$. Rehabilitation counseling programs not seeking CACREP approval may see a decline in enrollment from students desiring to work in the field of rehabilitation counseling due to limited opportunities in the field of counseling. Even though the merger is meant to strengthen the rehabilitation counseling profession, the emphasis on clinical mental health has many rehabilitation counseling educators and professors concerned about the future of rehabilitation counseling and the professional identity of rehabilitation counselors. Therefore, it is important to examine the self-efficacy of counselors-in-training at CORE accredited programs and practicing rehabilitation counselors who are graduates from CORE institutions and have not met state licensure and insurance provider requirements. Research strongly suggests that counseling self-efficacy influences client outcomes (McCarthy, 2014). Moreover, self-efficacy affects job satisfaction. Research on this topic is important in producing competent rehabilitation and clinical mental health counselors and filling vacancies in the workforce. In addition, high self-efficacy decreases burnout and reduces turnover rates.

\subsection{Review of Literature}

\subsubsection{CORE and CACREP}

The Council on Rehabilitation Education (CORE) was established in 1972 to solidify the roles, functions, and required competencies of rehabilitation counseling professionals (Stebnicki, 2009). According to Leahy and Szymanski (1995), CORE's purpose was to facilitate effective rehabilitation services to persons with disabilities by providing and promoting quality review of master's level rehabilitation counseling education programs. For over 40 years, CORE accredited at least 96 college and university rehabilitation counselor education programs at the master's degree level (Commission on Rehabilitation Counselor Certification, 2015).

In July, 2015, CORE and the Council for Accreditation of Counseling and Related Education Programs (CACREP) announced the merger between the two organizations in an effort to strengthen the counseling profession by establishing one unified accreditation process for counselor preparation programs (Commission on Rehabilitation Counselor Certification, 2015). As of July $1^{\text {st }}, 2017$, CACREP oversees the mission of both organizations. (Commission on Rehabilitation Counselor Certification, 2015).

CACREP was established in 1981 from several organizations under the American Personnel and Guidance Association (APGA). The initial set of CACREP Standards were developed by members in the Association of Counselor Education and Supervision (ACES), the American School Counselor Association (ASCA), and the American College Personnel Association (ACPA) (Bobby, 2013).

\subsubsection{Rehabilitation Counseling and Clinical Mental Health Counseling Professionals}

In 2008, there were 665,000 counselors within the United States (Smith, Reid, Henry, Dixon, \& Wright, 2013). Due to the current state of mental health, the need for competent mental health and rehabilitation counselors to serve the needs of individuals with mental illnesses is evident. According to the Bureau of Labor Statistics (2014), it is estimated the labor market will increase by $24 \%$ for mental health counselors, $19 \%$ for rehabilitation counselors, and $21 \%$ for substance abuse counselors by the year 2018 (Smith et al., 2013).

Mental health counselors promote optimum mental and emotional health by working with persons with mental illnesses through individual and group counseling sessions (Smith et al., 2013). In order to be effective and successful as a mental health counselor, counselors must exhibit self-control, concern for others, integrity, stress tolerance, and dependability (Bureau of Labor Statistics, 2014). 
The job functions of rehabilitation counselors consist of providing vocational counseling services, performing counseling intervention, performing community based rehabilitation activities, and conducting case management services (Leahy, Muenzen, Saunders, \& Strauser, 1995). Rehabilitation counseling is known as "the best kept secret" within the counseling field due to the number of job positions with various job titles that do not include the title rehabilitation counseling (Patterson, 2009). Both mental health counselors and rehabilitation counselors serve similar populations such as veterans (Patterson, 2009; Leahy et al., 2009). Government programs such as Tricare have significantly impacted the field of counseling.

\subsubsection{Tricare}

Establishing a system of medical care for active duty soldiers and families of active duty soldiers has been continuously revitalized since the late 1770's (Powers, 2011). Congress mandated families of active duty soldiers receive free medical care in 1884 by Army and contract surgeons (Powers, 2011). During World War II, there was a surge in military births, and the military healthcare system could not manage the birthing needs nor the large number of pediatric services required of young children (Lawrence, (Conley, \& Ruthman, 2011). As a result, Congress enacted the Emergency Maternal Infant Care Program (EMIC) (Powers, 2011). Wives of active duty soldiers received maternity care and medical care for infants up to one year of age and children (Powers, 2011).

Due to the Korean Conflict, the Dependents Medical Care Act was signed into law on December 7th, 1976 (Lawrence, Conley, \& Rothman, 2011). The Dependents Medical Care Act was renamed in 1967 to CHAMPUS and authorized psychiatric and ambulatory care for active-duty family members, retirees, and specific surviving family members of deceased active duty soldiers (Lawrence et al., 2011). In an effort to improve access to quality health care, Tricare was implemented (Powers, 2011). In the beginning, there were only three forms of Tricare: Tricare Prime; Tricare Extra; and Tricare Standard (Powers, 2011).

Tricare Prime is similar to a HMO plan and soldiers must enroll (Lawrence et al., 2011). Soldiers and family members of active duty soldiers may receive health care services on military bases and authorized installations (Powers, 2011). Tricare Extra allows soldiers to visit authorized providers, but requires extra fees (Lawrence et al., 2011). Lastly, Tricare standard allows soldiers to visit any medical provider, but it is the most expensive form of Tricare (Powers, 2011).

Mental health counselors providing counseling services to active duty soldiers and families insured by Tricare are mandated to meet certain requirements before being eligible to bill Tricare resulting from a federal regulation issued on December $27^{\text {th }}$, 2011 (Healthnet, n.d.). Counselors must obtain the Tricare Certified Mental Health Counselor credential, enabling counselors to provide independent care to Tricare enrollees after December 31, 2016 (CACREP, 2014). To be eligible for certification, counselors must have a master's degree in Clinical Mental Health Counseling or a Mental Health Counseling degree from a CACREP-accredited clinical mental health program (Council for Accreditation of Counseling and Related Educational Programs, 2014).

In addition, effective midnight January 1st, 2017, Tricare mental health providers must

meet at least one of the following three options: (a) Option One: Pass the NCMHCE and have a master's degree in Clinical Mental Health Counseling or a Mental Health Counseling degree from a CACREP-accredited clinical mental health counseling program; (b) Option Two: Pass the NCMHCE and have a master's or higher level degree from a regionally accredited program recognized by the Council for Higher Education Accreditation and complete a 3000 hour supervised clinical experience; (c) Option Three: Pass the NCE and have a master's degree in Clinical Mental Health Counseling or a Mental Health Counseling degree from a CACREP-accredited clinical mental health counseling program and complete a 3000 hour supervised clinical experience (Healthnet, n.d.).

After examining the eligibility requirements to obtain reimbursement for services from Tricare, rehabilitation counselors graduating from a CORE accredited program with only a CRC credential are not eligible to become TRICARE providers (Healthnet, n.d.). After the ruling by the Department of Veteran Affairs, the Department of the Army, and the Tricare Management Department, CORE collaborated with various accrediting counseling bodies to respond to the decision to exclude rehabilitation counselors from being eligible to bill Tricare (Lane, 2012). As a result, discussions surrounding the merger of CACREP and CORE further evolved (Lane, 2012). CACREP and CORE merged on July 20, 2015 in an effort to strengthen the counseling profession by establishing a single accreditation process for counseling programs (CACREP, 2015). Therefore, future rehabilitation counselors will need to seek additional licensures in an effort to be marketable to employers and insurance companies such as Tricare.

\subsubsection{Bandura's Self Efficacy Theory}

Bandura's Self-Efficacy Theory is a derivative of his Social Cognitive Theory (SCT) in which SCT details the origin of self-efficacy beliefs, the structure and properties of self-efficacy, its many effects, processes, and instructions on how to cultivate and embrace beliefs in an effort to create personal and social change (Bandura, 2012). 
Bandura (1977) theorized that behavioral changes can occur when successfully mediated through cognitive processes. From a counseling point of view, utilizing cognitive-based interventions may provide individuals with the knowledge, abilities, and skills to modify behaviors. On the other hand, behavioral changes, including knowledge and skills, will not occur if individuals do not believe that such behavioral changes can occur (Bandura, 1977).

Nilson and Duan (2007) defined counseling self-efficacy as a counselor's personal beliefs about the effectiveness of his or her counseling skills. Meyer (2015) believed counseling self-efficacy is a key component to influencing counselor development as it relates to knowledge, skills, and abilities. Skill development of counselors is often predicted by the counselor's personal perceptions of his or her knowledge, skills, and abilities (Meyer, 2015).

An individual's perception of self-efficacy is also a primary indicator of the amount of effort an individual is likely to devote to practicing and perfecting his or her knowledge, skills, and abilities. Individuals strive for personal and professional excellence based on their beliefs about potential outcomes and their ability to perform the necessary tasks to bring about those outcomes. Bandura (1977) stated if an individual continues to persevere and successfully meets goals, then feelings of self-efficacy will grow accordingly (Bandura, 1977). By contrast, individuals who have diminished or low perceptions of self-efficacy are more likely to seek out situations that do not exceed personal expectations (Strauser, 1995). Of interest to this study are the particular clinical practices which may challenge rehabilitation counseling and clinical mental health counselors-in-training who are enrolled in practicum/internship classes (Meyer, 2015).

Furthermore, within the counseling literature, the perceptions of master's level rehabilitation counseling intern's self-efficacy during the university-based clinical internship experience is lacking. Empirical evidence strongly suggests that counselor self- efficacy is directly related to counseling performance; however, there are significant gaps in understanding the impact of practicum/internship experiences upon rehabilitation and clinical mental health counseling student perceptions of self-efficacy.

\subsubsection{Ex Post Facto Design}

When conducting research using an ex post facto design, causal relationships among variables that are unable to be manipulated by the researcher are examined (Ritz, 2006). When setting up an ex post facto design, the researcher designs the study in order to compare two or more samples that are similar except for a specified factor that has happened previously (Ritz, 2006). Ex post facto research is performed when all data have been collected once the events of key interest have occurred (Ritz, 2006). Ex post factor designs focus on what has happened differently for similar groups of variables and then highlight whether the variables in each group are different (Ritz, 2006).

When examining the weaknesses of ex-post facto design, there are several limitations. First, in ex post facto design researchers lack control over independent variables (Ritz, 2006). Researchers are forced to accept facts and are unable to manipulate the variables or conditions to influence the facts (Ritz, 2006). Secondly, researchers may have difficulty determining that the most pertinent factor is included among the multiple factors being examined (Ritz, 2006). Thirdly, the outcome is not the result of one single variable, but is contingent among the combination or interaction of other variables (Ritz, 2006).

Next, the outcome may result, from one cause in one instance, and a different cause in another instance (Ritz, 2006). Therefore, the outcomes may result from multiple causes (Ritz, 2006). As a result, it may be due to additional factors not being observed or discovered (Ritz 2006). In ex post facto designs, variables are often classified into dichotomous groups in order to compare (Ritz, 2006). These studies often experience many problems such as being too vague or variable resulting in findings that are not useful for the researcher (Ritz, 2006). Lastly, conducting a comparative study in a natural setting does not allow researchers to control the subjects (Ritz, 2006). It is often difficult to locate existing groups or subjects similar in all aspects (Ritz, 2006).

\subsubsection{Counselor Activities Self-Efficacy Scale (CASES)}

In an effort to study the process of counselor development, Lent and his team used the helping skills model by Hill and Obrien (1999) to develop the Counselor Self Efficacy Scale (Lent, Hill, \& Hoffman, 2003). Lent and his team defined counselor self-efficacy as able to: (a) perform basic helping skills (item $n=15$ ), (b) manage session tasks (item $n=10$ ), and (c) negotiate challenging counseling situations and issues (item $n=16$ ) (Lent et al., 2003).

The CASES is a self-assessment which includes 41 items. Each item is measured on a 10-point Likert scale, ranging from zero (no confidence) to nine (extremely confident).

The helping skills sub-scale is comprised of exploration, insight, and action skills. Exploration counseling skills focus upon the counselor's ability to establish an effective counseling relationship and obtain beneficial information from the client. 
Insight counseling skills facilitate client understanding into the counseling issue; and action skills consist of the counselor's ability to assist the client in making positive changes in his or her thoughts, behaviors, and affect. (Lent et al., 2003).

The session management subscale assesses counselor ability to manage counseling tasks utilizing ten items (Lent \& et al., 2003). Next, the ability to be effective in challenging situations is assessed utilizing six items under the client distress domain (Lent \& et al., 2003). Lastly, the relationship conflict domain measures counselor's abilities to handle conflict within relationships utilizing a ten items (Lent \& et al., 2003).

\subsubsection{Impact upon Counselors-in-training and Professional Counselors}

Practicum and internship experiences in counseling education programs are designed to assist interns with increasing their counseling competency (Tang et al., 2004). The level of training a student receives and the quality of the practicum/internship experience contributes to a higher level of counseling self-efficacy (Tang et al., 2004). Over time, counselor training has a positive influence on self-efficacy (Tang et al., 2004). However, results from fourteen different studies found differences between counselor's self-efficacy and levels of training (Tang et al., 2004).

Initially, a few of the studies found a positive correlation between counseling self- efficacy and student training level (Tang et al., 2004). However, other studies found no correlation between counseling self-efficacy and student training level (Tang et al., 2004). In thirty-two different studies, Daniels and Larson (2001) found self-efficacy is related to counselor learning experiences such as counselor abilities, counselor anxiety, and counseling supervision.

Counseling anxiety is an emotional reaction related to an individual's situation (Larson \& Daniels, 2001). Instruments such as the Counseling Self-Estimate Inventory (COSE) is negatively related to anxiety (Al-Darmaki, 2005). Designed by Larson, Suzuki, Gillespie, Potenza, Bechtel, and Toulouse (1992), the COSE is used to measure counseling self-efficacy.

Validity estimates of the COSE confirmed counselor performance can be measured by the COSE and anxiety levels (Larson et al, 1992). Of interest to this study are results of counseling interns COSE scores increased by one standard deviation over the course of the practicum experience (Larson et al., 1992). Subsequently, pre-practicum trainees had lower scores than practicing counselors and psychologists (Larson et al., 1992). Next, individuals with higher self-efficacy scores from the COSE had at least one semester of supervision compared to individuals without supervision (Larson et al., 1992). Lastly, self-esteem and outcome expectations correlated with the COSE (Larson et al, 1992).

Larson and Daniels (1998) found counselors with a high self-efficacy experience more positive outcomes and less anxiety. It is imperative counselors have a high self-efficacy and reduced anxiety because anxiety can impair clinical judgement and job performance (Larson \& Daniels, 1998). When examining self-efficacy, counselors often focus on their performance (Larson \& Daniels, 1998). Some individuals make the mistake of overestimating their performance and skills (Urbani, Smith, Maddux, Smaby, Torres-Rivera, \& Crews, 2002). This may be due to individuals not having developed skills to access their competence (Urbani et al., 2012).

Moreover, some individuals tend to believe their good intentions over-rides their lack of competence (Urbani et al., 2012). Considering an individual's counseling self-efficacy, trainees often believe they are more or less effective with certain counseling populations (Lent, Hoffman, Hill, Treistman, Mount, \& Singley, 2006). Due to previous counseling experiences and personal preferences, trainees select particular populations to service based off of their personal niche and interests (Lent et al., 2006). When working with minorities, interns may have less confidence when providing counseling services to individuals different from them (Constantine, 2001).

As a result, intern counseling self-efficacy may fluctuate due to working with different minority groups

(Constantine, 2001). It is important counselors know how to help their clients and how to utilize effective counseling skills (Greason \& Cashwell, 2009). Being a successful counselor requires the ability to display empathy and maintain attentiveness when servicing clients (Greason \& Cashwell, 2009). A CACREP report showed 98 percent of counselor educators surveyed at accredited CACREP programs believed interns should be able to master empathy and attending skills (Greason \& Cashwell, 2009).

Being attentive is related to a plethora of cognitive processes which is difficult to define (Greason \& Cashwell, 2009). Counseling literature does not provide much guidance on how to nurture an individual's internal processes for controlling attention, cognitive and effective empathetic response (Greason \& Cashwell, 2009). Some researchers believe counseling students cognitive skills are left to chance by counseling educators (Greason \& Cashwell, 2009). By not nurturing counseling student's cognitive skills, students are at risk for decreased self-efficacy, ineffective counseling performance, and a decreased chance of learning new counseling skills (Greason \& Cashwell, 2009).

Concerning professional development of master's level counseling intern's self-efficacy, prepracticum students experience a heightened sense of self-efficacy over the length of their coursework (Melchert, Hays, Wiljanen, \& Kolocek, 
1996). Counseling interns express competence through demonstrating learned skillsets such as being attentive, paraphrasing and rephrasing client's messages, noting observations, providing reflections, and accurately summarizing client statements (Easton, Martin, \& Wilson, 2008).

In addition, students associated an excellent clinical experience with having a higher counseling self-efficacy (Melchert et al., 1996). Counseling students in their third and fourth year of graduate school experience higher self-efficacy than students in their first and second year (Melchert et al., 1996). Counseling interns with high self-efficacy rated supervisors to be more likeable and approachable (Melchert et al., 1996). Interns with low self-efficacy often expect supervisors to demonstrate competency and provide feedback (Melchert et al., 1996).

The ability to reorganize the feelings, motivation, and intentions of self relates to an individual's interpersonal and intrapersonal intelligence (Easton et al., 2008). Further, an individual's interpersonal and intrapersonal intelligence impacts a person's ability to discern the feelings, motivation, and intentions of others (Easton et al., 2008). Emotional intelligence consists of an individual's ability to identify the meaning of a person's feelings and assist the person with solving their issues (Easton et al., 2008).

\subsubsection{Impact of Professional Self-Efficacy upon Client Care}

Within the counseling field, client outcomes are significantly impacted by counselor self-efficacy (McCarthy, 2014). In a study conducted by Larson, Suzuki, Gillespie, Potenza, Bechtel, \& Toulouse, (1992), counselor responses from a self-efficacy inventory positively correlated to counselor performance. In another study, it was found self-efficacy among psychology students strongly correlated to client outcomes, but only in instances in which students received ongoing feedback from clients on their clinical skills (Reese, Usher, Bowman, Norsworthy, Halstead, Rowlands, \& Chisholm, 2009).

McCarthy (2014) conducted a study to determine (a) if there is a linear relationship between rehabilitation counselor self-efficacy and the number of client outcomes; (b) if the relationship is non-linear and is there an optimum level of rehabilitation counseling self-efficacy needed to obtain a successful client outcome and; (c) the demographic variables associated with counselor self-efficacy and counseling skills. McCarthy and his team found no correlation between counselor self-efficacy and a successful case closure through regression analysis (McCarthy, 2014).

However, a post-hoc correlation analysis revealed successful client outcomes were contingent upon rehabilitation counselors having a strong self-efficacy in executing microskills and dealing with difficult client behaviors (McCarthy, 2014). Counselor's perceived ability to use microskills such as building rapport and negotiating challenging client behavior, is an important element to assisting clients with changing their beliefs about their abilities and counseling skills with being able to successfully manage client behaviors (McCarthy, 2014). Counselors who demonstrate warmth, interest, and make reflective statements throughout sessions improve the work alliance between the counselor and client (McCarthy, 2014).

Therefore, it can be assumed micro-skills enhance the counseling relationship between counselor and client and assists with facilitating a positive outcome (McCarthy, 2014). As a result, self- efficacy of counselors is detrimental to the success of the counselor/client relationship and significantly influences the success of client outcomes (McCarthy, 2014).

Individuals must experience overcoming obstacles (e.g., practicum/internship class) in order to become resilient through perseverance and achieve mastery (Bandura, 2012). Practicing and demonstrating continuous success is essential for an individual to develop strong feelings of self- efficacy (Strauser, 1995). Once an individual develops a strong self-efficacy, efficacy expands into other areas outside of their learned competencies (Strauser, 1995). Of interest to this study are the long-term effects of practicum/internship experiences among students in CORE- accredited rehabilitation counseling programs and students in CACREP-accredited clinical mental health counseling programs upon student perceptions of counseling self-efficacy.

\section{Method}

\subsection{Participants}

To examine self-efficacy in counselors-in-training enrolled in CORE and CACREP accredited programs, purposeful sampling was employed to recruit participants for the study. Participants included rehabilitation and clinical mental health counselors-in-training, registered for practicum or internship classes, while enrolled in a CORE-accredited rehabilitation counseling program, or a CACREP-accredited clinical mental health counseling program.

Participants were recruited nationally through contacting practicum and internship coordinators at CORE and CACREP accredited rehabilitation and clinical mental health counseling programs. In addition, participants were recruited using counseling websites such as CES-NET. Power analysis suggested that for two independent groups, 128 participants (64 participants in each group) were desired in order to obtain at least a medium effect size (Thompson, 2002), with an a priori 
significance of .05 .

In order to be eligible to participate in the study, participants must have been currently enrolled in a practicum or internship course at a CORE or CACREP accredited program. In addition, participants must have been clinical mental health counseling majors or rehabilitation counseling majors.

Participants in this study consisted of CACREP $(n=49)$ and CORE $(n=27)$ practicum/internship counseling students who were currently enrolled in practicum and internship classes. Participants were invited to participate in the study through faculty internship coordinators at CORE and CACREP accredited institutions and CES-NET. An electronic format was utilized to disseminate research instruments.

The researcher contacted practicum and internship coordinators at CORE $(n=97)$ accredited universities and CACREP $(n=239)$ accredited universities in order to coordinate with practicum/internship classes, faculty, and students enrolled in rehabilitation counseling and clinical mental health counseling.

Participants who completed the survey were from the following states: (1) North Carolina; (2) Kansas; (3) Georgia; (4) Pennsylvania; (5) Texas; (6) Missouri; (7) Iowa; (8) Rhode Island; (9) Washington D. C.; (10) Michigan; (11) Texas; (12) North Dakota; (13) Idaho; (14) Florida; (15) New York; (16) Virginia; (17) Tennessee; (18) Indiana; (19) Arkansas; (20) Louisiana; (21) Oklahoma; (22) Massachusetts; (23) Maryland; (24) Colorado; (25) Kentucky; (26) Ohio; (27) Alabama; (28) California; (29) South Carolina.

A total of 175 participants began the survey. 108 participants completed the survey. After a final review of the results, a total of 76 participants met the criteria for the study.

\subsection{Instrumentation}

This study sought to investigate whether there were differences in feelings of self-efficacy between counselors-in-training, registered for practicum or internship classes, while enrolled in a CORE-accredited rehabilitation counseling program, or a CACREP- accredited clinical mental health counseling program. In order to measure self-efficacy, the Counselor Self-Efficacy Scale (CASES) was employed.

The Counselor Activities Self-Efficacy Scale (CASES) was administered to participants to assess self-efficacy. As stated previously, the CASES measures three areas including basic helping skills, management of session tasks, and negotiating challenging counseling situations and issues. In an effort to determine internal consistency, test-retest reliability, convergent validity, and discriminate validity estimates of the CASES, Lent and his associates administered the CASES to undergraduate students, master's level practicum students, and doctoral students in counseling psychology programs $(\mathrm{n}=$ 345) (Lent et al., 2003).

After examining the results, Lent and his associates obtained the following results: total score internal consistency ( $\mathrm{r}$ $=.97)$; exploration skills $(\mathrm{r}=.79)$; insight skills $(\mathrm{r}=.85)$; action skills $(\mathrm{r}=.83)$; session management $(\mathrm{r}=.94)$; client distress $(\mathrm{r}=.94)$; and relationship conflict $(\mathrm{r}=.92)$ (Lent et al., 2003). In addition, Cronbach alpha coefficient was computed $(\mathrm{r}=.98)$ (Lent et al., 2003).

When examining the convergent and discriminant validity, large correlations between pairs of scales were observed (Lent et al, 2003). Scales for the CASES total score and COSE total score had a high correlation $(r=.76)$ (Lent et al, 2003). However, there were small correlations between the CASE scales and the COSE's Cultural Competence and Awareness of Values scale (Lent et al., 2003). In reference to the criterion-related validity, outcome expectations were small for correlations between the CASES scale to outcome expectations (Lent et al., 2003).

A range of .35 to .47 existed between CASES scales and interests in therapy activities (Lent et al., 2003). Moreover, a range of .11 to .31 was observed between CASES scales to the counseling relatedness of participants intended career choices (Lent et al., 2003). Lastly, Lent et al. (2003) found a moderate relationship between most of the CASES scales and the experience of negative and positive affect during counseling. Ranges were between -.20 to-. 42 and .26 to .39 (Lent et al., 2003).

\subsection{Procedures}

After securing approval from the Institutional Review Board (IRB) at the University of North Carolina Agricultural and Technical State University authorizing continuation of the study, the primary researcher contacted internship coordinators at CACREP and CORE accredited institutions via email. A list of CACREP and CORE accredited institutions was obtained from the CORE and CACREP website.

Contact information for program coordinators were obtained from the CORE website. In order to obtain contact information for internship coordinators at CACREP institutions, the primary researcher contacted counseling departments at each CACREP institution and obtained contact information for internship coordinators via email. 
An initial email was sent to internship coordinators requesting assistance with disseminating the survey to students enrolled in practicum and internship courses. The initial email included a description of the study, participant eligibility requirements, a consent form, and a link to the demographic survey and CASES. Internship coordinators that failed to respond within a week were sent a follow-up email and contacted via phone by the primary researcher. Internship Coordinators were initially contacted on February $4^{\text {th }}, 2016$.

Requests to participate in the study were sent to every CACREP and CORE program listed on each accrediting body's website. If internship coordinators failed to respond, a reminder email was sent weekly through February $18^{\text {th }}, 2016$. A phone call was made to unresponsive internship coordinators on February $11^{\text {th }}, 2016$ in addition to a follow-up call made on February $18^{\text {th }}, 2016$.

For institutions agreeing to participate in the study, a follow-up email was sent thanking each institution for agreeing to participate in the study and answering any questions the internship coordinator may have had. Once internship coordinators agreed to distribute the link to the students, students had the option of the participating in the study. Once students clicked on the link, students were directed to the consent form outlining the details of the study (attachment). If students agreed to participate in the study, students were directed to the CASES. If students did not agree to participate in the study, those results were not included in the final data. The survey was posted for three weeks on Qualtrics. At the end of the three weeks, the survey was closed.

\section{Results}

In the Results section, summarize the collected data and the analysis performed on those data relevant to the discourse that is to follow. Report the data in sufficient detail to justify your conclusions. Mention all relevant results, including those that run counter to expectation; be sure to include small effect sizes (or statistically nonsignificant findings) when theory predicts large (or statistically significant) ones. Do not hide uncomfortable results by omission. Do not include individual scores or raw data with the exception, for example, of single-case designs or illustrative examples. In the spirit of data sharing (encouraged by APA and other professional associations and sometimes required by funding agencies), raw data, including study characteristics and indivldual effect sizes used in a meta -analysis, can be made available on supplemental online archives.

\subsection{Recruitment}

\begin{tabular}{|c|c|c|}
\hline Activity & Date & Justification \\
\hline IRB Approval & $1-27-2016$ & Approval Request sent on 12-5-2015 \\
\hline Initial Email & 2-04-2016 & Sent email to point of contacts. \\
\hline Second Email & 2-11-2016 & $\begin{array}{l}\text { Sent a reminder email to point of contacts } \\
\text { who were unresponsive. }\end{array}$ \\
\hline Initial Phone Call & 2-11-2016 & $\begin{array}{l}\text { Attempted to reach point of contacts via } \\
\text { phone. }\end{array}$ \\
\hline Third Email & $2-18-2016$ & $\begin{array}{l}\text { Sent a reminder email to point of contacts } \\
\text { who were unresponsive. }\end{array}$ \\
\hline Second Phone Call & $2-18-2016$ & Attempt to reach point of contacts via phone. \\
\hline Survey Closed & $3-01-2016$ & Closed Survey on Qualtrics \\
\hline
\end{tabular}

The purpose of this investigation was to examine perceptions of self-efficacy between master's level rehabilitation counseling practicum and internship students enrolled in CORE-accredited programs and master's level clinical mental health counseling practicum and internship students enrolled in CACREP-accredited programs. The study sought to determine any differences in the total perceived self-efficacy total and subscale scores between CACREP practicum/internship students $(n=49)$ and CORE practicum/internship students $(n=27)$.

Although there were mean differences between CACREP and CORE practicum/internship perceived self-efficacy total and subscale scores (Table 1), independent sample $t$-tests revealed no significant differences between perceived self-efficacy total and subscale scores between CACREP and CORE practicum and internship students (Table 2).

Table 1. CACREP and CORE Self Efficacy Means Comparison Table

\begin{tabular}{lcc}
\hline Group & CACREP & CORE \\
\hline Total Self Efficacy Scores & 7.72 & 7.22 \\
Helping Skills Scores & 7.84 & 7.52 \\
Session Management Scores & 8.05 & 7.68 \\
Challenging Situations & 7.85 & 7.25 \\
\hline
\end{tabular}


Table 2. Research Questions by Hypotheses by Scales by Measures

\begin{tabular}{|c|c|c|c|}
\hline Research Question & Hypothesis & Scale & Measure \\
\hline $\mathrm{R}^{\mathrm{I}}$ Is there a significant difference & $\mathrm{H}^{\mathrm{I}}$ There is no significant difference & Counselor & \\
\hline between CORE and CACREP total & between CORE and CACREP total & Activities & $t=1.922$ \\
\hline self-efficacy scores? & self-efficacy scores. & Self-Efficacy Scale & $p=.059 *$ \\
\hline $\mathrm{R}^{1}$ Is there a significant difference & $\mathrm{H}^{\mathrm{l}}$ There is no significant difference & Counselor & $t=1.219$ \\
\hline $\begin{array}{c}\text { between CORE and CACREP combined } \\
\text { helping skills scores? }\end{array}$ & $\begin{array}{l}\text { between CORE and CACREP } \\
\text { combined helping skills scores. }\end{array}$ & $\begin{array}{c}\text { Activities } \\
\text { Self-Efficacy Scale }\end{array}$ & $\begin{array}{l}t=1.219 \\
p=.227 *\end{array}$ \\
\hline $\mathrm{R}^{1}$ Is there a significant difference & $\begin{array}{l}\mathrm{H}^{1} \text { There is no significant difference } \\
\text { between CORE and CACREP }\end{array}$ & Counselor & $t=-1.142$ \\
\hline $\begin{array}{c}\text { between CORE and CACREP combined } \\
\text { session management scores? }\end{array}$ & $\begin{array}{c}\text { combined session management } \\
\text { scores. }\end{array}$ & $\begin{array}{l}\text { Activities } \\
\text { Self-Efficacy Scale }\end{array}$ & $p=.257^{*}$ \\
\hline $\begin{array}{l}\mathrm{R}^{1} \text { Is there a significant difference } \\
\text { between CORE and CACREP combined } \\
\text { challenging situations scores? }\end{array}$ & $\begin{array}{c}\mathrm{H}^{1} \text { There is no significant difference } \\
\text { between CORE and CACREP } \\
\text { combined challenging situations } \\
\text { scores. }\end{array}$ & $\begin{array}{c}\text { Counselor } \\
\text { Activities } \\
\text { Self-Efficacy Scale }\end{array}$ & $\begin{aligned} t & =.887 \\
p & =.378^{*}\end{aligned}$ \\
\hline
\end{tabular}

*Retain the null hypothesis.

\subsection{Results of Analysis to Address Research Questions}

Research question one sought to determine if there is a significant difference $(p \leq .05)$ between CORE-accredited rehabilitation and CACREP-accredited clinical mental health counseling practicum/internship total self-efficacy score. Total scores were reviewed from the CASES survey to determine significant differences by reviewing the total scores of CORE and CACREP participants helping skills, management of the counseling session, and management of clients.

Participants conducted a self-assessment to report confidence in performing counseling activities such as helping skills, session management, and handling challenging situations in counseling using a 9 point Likert scale. The scale ranged from $0=$ no confidence at all to $9=$ complete confidence. To determine the perceived self-efficacy score of each subscale of the CASES, the total points were added for each subscale and then the average was calculated for each participant. If averaged scores were high, then it meant participants had a high self-efficacy. Even though there was not a significant difference between the total perceived self-efficacy score for all CACREP $(n=49 ; M=7.72)$ and CORE participants $(n=$ 27; $M=7.22$ ), the self-efficacy of CACREP participants was higher than CORE participants. See Table 1. Both samples had similar experiences as it related to helping skills, session management, and management of clients, but CACREP participants were more confident.

An independent $t$-test was conducted to compare the means between both treatment groups, CORE and CACREP. Whereas results technically indicated no significance between the means for the total self-efficacy scores for both groups ( $p=.059$.), the significance level suggested further study is warranted. Thompson (2002) discussed three types of significance, i.e., statistical, practical, and clinical. Statistical significance, or lack thereof, should be viewed through the lens of the other two types of significances. In other words, counselor educators may want to consider the practical differences in counselor preparation when it comes to self-efficacy. MANOVA was also used to test the significance of the total self-efficacy score between the treatment groups. The $f$-statistic was not significant $(p=.059)$. See Tables 16 and 17 .

\subsubsection{Helping Skills}

Research question two sought to determine if there is a significant difference $(p \leq .05)$ between CORE-accredited rehabilitation and CACREP-accredited clinical mental health counseling practicum/internship helping skills self-efficacy score. In the helping skills subscale on the CASES, participants self-assessed helping skills such as use of open questions, listening, and attending skills. No significant difference was found between groups $(p=.227)$ (Tables 16 and 17).

\subsubsection{Session Management Skills}

Next, research question three sought to determine if there is a significant difference $(p \leq .05)$ between CORE-accredited rehabilitation and CACREP-accredited clinical mental health counseling practicum/internship session management self-efficacy score. Participants used the session management subscale to self-assess skills such as helping clients explore thoughts and feelings and building a clear conceptualization of clients. No significant difference was found between groups ( $p=.257$ ) (Tables 16 and 17).

\subsubsection{Counseling Challenging Situations}

Research question four posed the following question: "Is there a significant difference $(p \leq .05)$ between CORE-accredited rehabilitation and CACREP-accredited clinical mental health counseling practicum/internship challenging situations self-efficacy score?" Participants self-assessed skills used when counseling clients in challenging situations. Clients may present with depression, sexual abuse, and disturbed thinking. No significant difference was found between groups $(p=.378)$ (Tables 16 and 17). 
Table 16. CACREP and CORE CASES Independent Samples T-Test

\begin{tabular}{lll}
\hline Group & $t$ & Sig. (2-tailed) \\
\hline CORE/CACREP Combined Total Self Efficacy Score & 1.922 & .059 \\
CORE/CACREP Combined Helping Skills Score & 1.219 & .227 \\
CORE/CACREP Combined Session Management Scores & -1.142 & .257 \\
CORE/CACREP Combined Challenging Situations Scores & .887 & .378 \\
\hline
\end{tabular}

Table 17. CORE and CACREP Variables of Self-Efficacy (MANOVA)

\begin{tabular}{lll}
\hline Dependent Variable & $f$ & Sig. (2-tailed) \\
\hline Combined Total Self-Efficacy Score & 3.692 & .059 \\
Combined Helping Skills & 1.485 & .227 \\
Combined Session Management & 1.303 & .257 \\
Combined Counseling Challenging Situations & .787 & .378 \\
\hline
\end{tabular}

Self-efficacy is an important concept in counselor preparation. The construct of self-efficacy consists of a person's individual beliefs regarding personal abilities to perform and have control over specific tasks (Bandura, 1991). Within the field of counseling, research has reported that a person's personality traits impact client outcome (Grencavage \& Norcross, 1990; Lambert, 1989; Stein \& Lambert, 1995). When examining self-efficacy, character traits are able to be used to train and select counselors (Urbani, et. al, 2012). Additional character traits such as a counselor's conceptual level and ego are able to be used to train and select counselors (Urbani et. al, 2012). As previously stated in Chapter 2, Bandura (2012) believed that self-efficacy regulates human functioning and personal capabilities through mastery experiences, social modeling, social persuasion, and choice processes.

Little information surrounding differences in perceptions of self-efficacy between CORE- and CACREP-trained practicum and internship students has been reported in the professional literature. This study aimed to determine perceptions of self-efficacy between these two groups. Moreover, and of interest to this study, were the perceptions of self-efficacy among CACREP and CORE practicum and internship students and any group differences in self-efficacy scores. Practicum and internship students residing in CACREP- and CORE-accredited programs were assessed for self-efficacy and compared. Analysis indicated no statistical difference between groups, although on average, CACREP-trained practicum and internship students scored higher on self-efficacy total and subscale scores. Indeed, CACREP students averaged a score of 7.72 and CORE students, a score of 7.22 (scale $=0-9$ ). Lent et. al (2003) designed the Counseling Activities Self Efficacy Scale (CASES). In the scoring directions, Lent and his team indicated that where scores are higher, greater levels of the construct of self-efficacy were present. Anyone possessing a score between seven and nine may be considered as having "complete confidence." Many job tasks of rehabilitation counselors and clinical mental health counselors overlap when serving consumers. It is interesting to note CACREP participants felt more confident than CORE participants in performing helping skills, session management skills, and handling challenging situations in counseling. Whereas study results are preliminary, rehabilitation counseling educators may wish to consider study findings to determine areas for improvement in clinical training.

These results have additional counselor educator and clinical implications. According to Lent et. al (2003), counseling trainee clinical performance is affected by self-efficacy. Larson and Daniels (1998) reported practicum experiences have a positive impact on counselor self-efficacy. In addition, counseling self-efficacy explains specific aspects of trainee career development (Heppner, Obrien, Hinkelman, \& Flores, 1996; Lent et. al, 2003). Larson and Daniels (1998) found counselor self-efficacy positively correlated with counselor performance and counseling knowledge. To some degree, results from this study contradict previous research. On average, CORE practicum and internship students spent 65.5 hours per week in counseling-related learning experiences, while CACREP practicum and internship students spent almost 60 hours per week in similar activities. Nonetheless, the CACREP group averaged higher scores across self-efficacy measures. (See Table 1.)

Prior research has also found more experienced counselors exhibit greater self-efficacy than beginning counselors (Larson \& Daniels, 1998). Findings from this study are somewhat consistent with this information.

Since this was the first study to explore perceptions of self-efficacy between rehabilitation counseling practicum and internship students enrolled at CORE-accredited universities and clinical mental health counseling practicum and internship students enrolled at CACREP-accredited universities, there were not any comparison groups to measure perceived counselor self-efficacy across all three dimensions of the CASES. The treatment groups in this study were specific in nature because participants were required to be current practicum or internship students enrolled at a CORE or CACREP accredited university. These findings may be pertinent to universities participating in the CORE conversion process because CACREP students had a higher counseling self-efficacy.

Bandura (2012) stated seeking challenges and encountering a good balance of success and failures enables people to build resilience. Even though CACREP self-efficacy scores were higher than CORE self-efficacy scores across all domains, the 
difference in sample means was not significant. In other words, study findings do not necessarily suggest that CORE participants fail to seek challenging counseling opportunities nor encounter a positive balance of success and failures to build resilience or competency (Bandura, 2012; Strauser, 1995).

\section{Study Limitations}

This study has several design limitations. First, this is an ex post facto design, and assignment to groups (i.e., CORE and CACREP) is not random. In quasi-experimental designs, the assumption is that the "treatment" has already been applied. (In this case, the treatment is assignment to CORE or CACREP training.) Inherent to this design is difficulty in controlling for confounding variables which may better describe differences between groups.

Also, there is sample bias. Participation in this study was voluntary. Where participation is predicated upon willingness to participant, it is important to wonder about those who choose not to participate. Next, the power analysis of 64 for each participant group was not achieved. Only 76 participants-CORE $(n=27)$ and CACREP $(n=49)$-were included in the study. Requests for participation were sent to internship coordinators at every CORE and CACREP accredited program identified on the accrediting body websites. Many universities did not respond to requests for participation. This may be due to internship coordinators being on leave, incorrect contact information, or not having interest in the study. Since CORE disseminated on July $1^{\text {st }}, 2017$, this study is unable to be replicated.

Further, participants self-assessed helping skills, session management skills, and counseling challenging situations skills on the CASES. Students often overestimate counseling abilities according to Barnes (2004). A review of mean scores reported participants in both treatment groups have high self-efficacy. Students may have responded to items on the CASES in the desire to assist the researcher with obtaining favorable results or to increase the appearance of counseling competency and self-efficacy (i.e., Hawthorne effect).

Several internship coordinators declined to participate in the study due to not meeting the eligibility requirements for the study. In addition, a few CORE-accredited universities listed on the CORE website were no longer accredited by CORE. A significant impediment to study implementation was having to rely on internship coordinators to communicate with internship and practicum students. A request for participants was posted on CES-NET. However, the primary researcher was unable to track respondents through this system or follow-up directly with interested parties. Further, the instruments used for this study were administered electronically. As a result, the primary researcher was not able to screen participants to eliminate invalid or unusable responses.

There is instrument bias. Although the CASES has adequate reliability and (convergent and discriminant) validity, the instrument has demonstrated poor criterion-referenced validity. The instrument also focuses upon helping skills, management of counseling session, and management of client crises. It is possible that these constructs do not fully cover every element counselor-in-training efficacy.

Another limitation to this study was the use of technology. In the computer software system used to administer the instruments, Qualtrics, some respondents did not complete the survey. This may have been due to internet connectivity issues, computer compatibility issues, or Qualtrics system failure. As a result, the mobile phone option to take the survey is faulty.

The last limitation to this study is perceptions of self-efficacy between rehabilitation counseling interns (CORE) and clinical mental health counseling interns (CACREP) could be related to the sheer novelty of the study. Due to gaps in the literature, the researcher was unable to identify problems or errors that may have been encountered by other researchers.

\section{References}

Al-Darmaki, F. (2005). Counseling self-efficacy and its relationship to anxiety and solving problem- in united arab emirates. International Journal for the Advancement of Counseling, 27(2), 323-335. https://doi.org/10.1007/s10447-005-3190-6

Bandura, A. (1977). Self-efficacy: Toward a unifying theory of behavioral change. Psychological Review, 84(2), 191-215. https://doi.org/10.1037/0033-295X.84.2.191

Bandura, A. (1991). Social cognitive theory of self-regulation. Organizational Behavior and Human Decision Processes, 50, 248-287. https://doi.org/10.1016/0749-5978(91)90022-L

Bandura, A. (2012). On the functional properties of perceived self-efficacy revisited. Journal of Management, 38(1), 98-44. https://doi.org/10.1177/0149206311410606

Bobby, C. L. (2013). The evolution of specialties in the cacrep standards: CACREP's role in unifying the profession. Journal of Counseling \& Development, 91(1), 35-43. https://doi.org/10.1002/j.1556-6676.2013.00068.x

Bureau of Labor Statistics. 2014. Wage data and 2012-2022 employment projections. Bureau of Labor Statistics, U.S. 
Department of Labor. Occupational Outlook Handbook, 2014-15 Edition.

Burke, H. S., Degeneffe, C. E., \& Olney, M. F. (2009). A new disability for rehabilitation counselors: Iraq war veterans with traumatic brain injury and post-traumatic stress disorder. Journal of Rehabilitation, 75(3), 5-14.

Commission on Rehabilitation Counselor Certification (2015). Rehabilitation counseling scope of practice. Retrieved from https://www.crccertification.com/scope-of-practice

Constantine, M. G. (2001). The relationship between general counseling self-efficacy and selfperceived multicultural counseling competence in supervisees. Clinical Supervisor, 20(2), 81. https://doi.org/10.1300/J001v20n02_07

Council for Accreditation of Counseling and Related Education Programs (2015). CACREP/CORE merger updates. Retrieved from http://www.cacrep.org/wp-content/uploads/2012/10/Press-Release-10.-22.-15.pdf

Council for Accreditation of Counseling and Related Educational Programs (2014). Vision, mission and core services. Retrieved from http://www.cacrep.org/about-cacrep/visionmission-and-core-values/

Daniels, J. A., \& Larson, L. M. (2001). The impact of performance feedback on counseling self-efficacy and counselor anxiety. Counselor Education and Supervision, 41(2), 120-130. https://doi.org/10.1002/j.1556-6978.2001.tb01276.x

Easton, C., Martin Jr, W. E., \& Wilson, S. (2008). Emotional intelligence and implications for counseling self-efficacy: Phase II. Counselor Education \& Supervision, 47(4), 218-232. https://doi.org/10.1002/j.1556-6978.2008.tb00053.x

Greason, P. B., \& Cashwell, C. S. (2009). Mindfulness and counseling self-efficacy: The mediating role of attention and empathy. Counselor Education \& Supervision, 49(1), 2-19. https://doi.org/10.1002/j.1556-6978.2009.tb00083.x

Grencavage, L. M., \& Norcross, J. C. (1990). Where are the commonalities among therapeutic common factors? Professional Psychology: Research and Practice, 21, 372-378. https://doi.org/10.1037/0735-7028.21.5.372

Healthnet, (n.d.). Change in mental health counselor providers. Retrieved from https://www.hnfs.com/content/hnfs/home/tn/prov/bh/mhc_requirements.html

Heppner, M. J., O'Brien, K. M., Hinkelman, J. M., \& Flores, L. Y. (1996). Training counseling psychologists in career development: Are we our own worst enemies? The Counseling Psychologist, 24, 105-125. https://doi.org/10.1177/0011000096241007

Heppner, P. P. Wampold, D. M., \& Kivlighan, B. E. (2008). Research Design in Counseling. Belmont, CA: Brooks/Cole.

Lambert, M. J. (1989). The individual therapists contribution to psychotherapy process and outcome. Clinical Psychology Review, 9, 469-485. https://doi.org/10.1016/0272-7358(89)90004-4

Larson, L. M., \& Daniels, J. A. (1998). Reviews of the counseling self-efficacy literature. The Counseling Psychologist, 26, 179-118. https://doi.org/10.1177/0011000098262001

Larson, L. M., Suzuki, L. A., Gillespie, K. N., Potenza, M. T., Bechtel, M. A., \& Toulouse, A. L. (1992). Development and validation of the counseling self-estimate inventory. Journal of Counseling Psychology, 39(1), 105-120. https://doi.org/10.1037/0022-0167.39.1.105

Lawrence, J. K., Conley, L. \& Rothman, A. (2011). Restoring tricare. Center for American Progress. Retrieved from http://mldc.whs.mil/public/docs/library/health/2011_-_Center_for_American_Progress_-_Restoring_TRICARE.pd $\mathrm{f}$

Leahy, M. J., \& Szymanski, E. M. (1995). Rehabilitation Counseling: Evolution and Current Status. Journal of Counseling \& Development, 74(2), 163-166. https://doi.org/10.1002/j.1556-6676.1995.tb01843.X

Leahy, M. J., Muenzen, P., Saunders, J. L., \& Strauser, D. R. (2009). Essential knowledge domains underlying effective rehabilitation counseling practice. Rehabilitation Counseling Bulletin, 52(2), 95-106. https://doi.org/10.1177/0034355208323646

Lent, R. W., Hill, C. E., \& Hoffman, M. A. (2003). Development and validation of the counselor activity self-efficacy scales. Journal of Counseling Psychology, 50(1), 97-108. https://doi.org/10.1037/0022-0167.50.1.97

Lent, R. W., Hoffman, M. A., Hill, C. E., Treistman, D., Mount, M., \& Singley, D. (2006). Client-specific counselor self-efficacy in novice counselors: Relation to perceptions of session quality. Journal of Counseling Psychology, 53, 453-463. https://doi.org/10.1037/0022-0167.53.4.453

McCarthy, A. K. (2014). Relationship between rehabilitation counselor efficacy for counseling skills and client outcomes. Journal of Rehabilitation, 80(2), 3-11. 
Melchert, T. P., Hays, V. L., Wiljanen, L. M., \& Kolocek, A. K. (1996). Testing models of counselor development with a measure of counseling self-efficacy. Journal of Counseling \& Development, 74(6), 640-644. https://doi.org/10.1002/j.1556-6676.1996.tb02304.x

Patterson, J. B. (2009). Professional identity and the future of rehabilitation counseling. Rehabilitation Counseling Bulletin, 52(2), 129-132. https://doi.org/10.1177/0034355208323949

Reese, R. J., Usher, E. L., Bowman, D. C, Norsworthy, L.A., Halstead, J. L., Rowlands, S. R., \& Chisholm, R. R. (2009). Using client feedback in psychotherapy training: An analysis of its influence on supervision and counselor self-efficacy. Training and Education in Professional Psychology, 3(3), 157-168. https://doi.org/10.1037/a0015673

Selander, J., Mametoft, S., Asell, M., \& Selander, U. (2008). Internal locus of control and vocational rehabilitation. Work, 30, 149-155.

Smith, T. J., Reid, J. A., Henry, R. G., Dixon, C. G., \& Wright, T. J. (2013). Evaluating curricular influence on preparation for practice, career outcomes, and job satisfaction: Results from an alumni survey of a 40-year rehabilitation and mental health counseling program. Rehabilitation Research, Policy \& Education, 27(1), 435715. https://doi.org/10.1891/2168-6653.27.1.43

Stebnicki, M. A. (2009). A call for integral approaches in the professional identity of rehabilitation counseling. Rehabilitation Counseling Bulletin, 52(2), 133-137. https://doi.org/10.1177/0034355208324263

Stein, D. M. \& Lambert, M. J. (1995). Graduate training in psychotherapy: Are therapy Outcomes enhanced? Journal of Counseling Psychology, 63, 182-196.

Strauser, D. R. (1995). Applications of self-Efficacy theory in rehabilitation counseling. Journal of Rehabilitation, 61(1), 7-11.

Tang, M., Addison, K. D., LaSure-Bryant, D., Norman, R., O'Connell, W., \& Stewart -Sicking, J. A. (2004). Factors that influence self-efficacy of counseling students: An exploratory study. Counselor Education \& Supervision, 44(1), 70-80. https://doi.org/10.1002/j.1556-6978.2004.tb01861.x

Tarvydas, V., Leahy, M., \& Saunders, J. (2004). A comparison of the ethical beliefs of certified rehabilitation counselors and national certified counselors. Rehabilitation Counseling Bulletin, 47(4), 234-254. https://doi.org/10.1177/00343552040470040501

Thompson, B. (2002). "Statistical," practical," and "clinical": how many kinds of significance do counselors need to consider? Journal of Counseling and Development, 80, 64-71. https://doi.org/10.1002/j.1556-6678.2002.tb00167.x

Urbani, S., Smith, M. R., Maddux, C. D., Smaby, M. H., Torres-Rivera, E., \& Crews, J. (2002). Skills-based training and counseling self-efficacy. Counselor Education \& Supervision, 42(2), 92.

https://doi.org/10.1002/j.1556-6978.2002.tb01802.x

\section{Copyrights}

Copyright for this article is retained by the author(s), with first publication rights granted to the journal.

This is an open-access article distributed under the terms and conditions of the Creative Commons Attribution license which permits unrestricted use, distribution, and reproduction in any medium, provided the original work is properly cited. 